Article

\title{
Purification and Characterisation of Badger IgA and Its Detection in the Context of Tuberculosis
}

\author{
Deanna Dalley $^{1}$, Sandrine Lesellier ${ }^{2}$, Francisco J. Salguero ${ }^{3} \mathbb{D}$ and Mark A. Chambers ${ }^{1,4, * \mathbb{D}}$ \\ 1 Department of Bacteriology, Animal and Plant Health Agency, Addlestone, Surrey KT15 3NB, UK; \\ deanna.dalley@apha.gov.uk \\ 2 Laboratoire de la Rage et de la Faune Sauvage de Nancy (LRFSN), ANSES, 54220 Malzéville, France; \\ sandrine.lesellier@anses.fr \\ 3 Public Health England, Porton Down, Salisbury SP4 0JG, UK; Javier.Salguero@phe.gov.uk \\ 4 School of Veterinary Medicine, Faculty of Health and Medical Sciences, University of Surrey, \\ Guildford GU2 7AL, UK \\ * Correspondence: mark.chambers@apha.gov.uk
}

Received: 30 September 2019; Accepted: 31 October 2019; Published: 2 November 2019

\begin{abstract}
European badgers are a wildlife reservoir of bovine tuberculosis in parts of Great Britain. Accurate diagnosis of tuberculosis in badgers is important for the development of strategies for the control of the disease. Sensitive serological tests for badger TB are needed for reasons such as cost and simplicity. Assay of mucosal IgA could be useful for diagnosing respiratory pathogens such as Mycobacterium bovis and for monitoring the response to mucosal vaccination. To develop an IgA assay, we purified secretory IgA from badger bile, identifying secretory component (SC), heavy chain (HC) and light chain (LC), at 66, 46 and $27 \mathrm{Kda}$, respectively, on the basis of size comparison with other species. Monoclonal antibodies (mAbs) were generated to purified IgA. We selected two for ELISA development. The detection limit of the IgA-specific mAbs was found to be approximately $20 \mathrm{ng} / \mathrm{mL}$ when titrated against purified badger bile. One monoclonal antibody specific for badger IgA was used to detect IgA in serum and tracheal aspirate with specificity to an immunodominant antigen of M. bovis. An M. bovis infection dose-dependent IgA response was observed in experimentally infected badgers. IgA was also detected by immunohistochemistry in the lungs of bTB-infected badgers. With further characterisation, these represent new reagents for the study of the IgA response in badgers.
\end{abstract}

Keywords: immunoglobulin A; badger; tuberculosis

\section{Introduction}

In parts of Great Britain and Ireland, the European badger (Meles meles) constitutes a reservoir of infection for Mycobacterium bovis and a potential source of infection to cattle [1-3]. Accurate diagnosis of $M$. bovis infection in badgers is an important component of strategies to control bTB in this species. Culture isolation of $M$. bovis remains the "gold-standard" diagnostic test but this is only sensitive when post-mortem tissue samples are used. Thus, sensitive in vitro diagnostics that can be used to test live animals are still required.

Assays based on measurement of a cellular immune response are commonly used for the diagnosis of TB in cattle, humans and other mammals. In badgers, we have developed an interferon-gamma $(\mathrm{IFN} \gamma)$ release assay (IGRA) for bTB detection in badgers [4]. With a sensitivity of up to $81 \%$ and a specificity of $94 \%[5,6]$, it is the most accurate bTB test that can be performed on live badgers. However, as an alternative diagnostic approach, assays measuring serological responses offer several advantages. These include test rapidity and ease of use and the stability of antibodies during sample transport, processing and storage. Antibody-based assays for badger TB have been developed previously $[7,8]$ 
but historically have lacked sensitivity (reviewed in $[9,10]$ ). Although more recent developments show promising enhancement in test accuracy [11], there still remains a need for more sensitive serological-based diagnostic tests for badger TB.

Most serological assays developed to date for badgers have evaluated the immunoglobulin G (IgG)-mediated humoral response against mycobacterial antigens. For example, the badger bTB ELISA measures IgG recognition of MPB83, a glycosylated lipoprotein that is a major target of the antibody response in $M$. bovis infected badgers [12], later confirmed using a multi-antigen print immunoassay (MAPIA) [13]. However, there is justification for the evaluation of the IgA response to mycobacterial infection as the basis of an improved serodiagnostic test for badger TB. When Conde et al. evaluated the usefulness of detection of serum IgA and serum IgG antibodies directed against the mycobacterial P-90 antigen for the diagnosis of pulmonary TB in people, they found that an IgA-based ELISA was more sensitive and specific than one based on IgG [14]. IgA is the predominant Ig isotype in human mucosal tissue and comprises about $60 \%$ of the total immunoglobulin produced in humans [15]. Since M. bovis is primarily a respiratory pathogen in badgers [16], it would be beneficial to develop an immunological test to detect the local response to infection in badgers. Furthermore, immunoglobulins, including IgA have been localised by immunohistochemical staining in bovine granulomatous lesions caused by $M$. bovis [17].

Studies in rats have revealed bile to be an abundant source of both secretory $\operatorname{IgA}(\operatorname{sg} \mathrm{A})$ and free secretory component (SC) [18]. For this reason, together with its accessibility and abundance, badger bile was chosen as the source of sIgA for the development of the ELISA for badgers. In this study, a panel of monoclonal antibodies (mAbs) was raised against badger sIgA purified from bile. The mAbs were then screened using purified sIgA and IgG in order to identify suitable mAbs for ELISA development. One mAb with reactivity to sIgA was selected to detect IgA in serum and tracheal aspirates by ELISA with specific recognition of recombinant antigen MPB83. This mAb was also peroxidase labelled and used to detect IgA by immunohistochemistry within M. bovis induced granulomas in lungs from badgers.

\section{Materials and Methods}

\subsection{Purification of $\operatorname{sg} A$ from Badger Bile}

Bile was obtained from a bTB-free badger post mortem. Badger bile was clarified by centrifugation and then concentrated five-fold using a stirred cell Amicon concentrator (Sigma-Aldrich Company Ltd., Dorset, UK) without precipitation of the proteins. The concentrated preparation was dialysed three times against $2 \% \mathrm{NaCl}$, buffered with $0.02 \mathrm{M}$ Tris- $\mathrm{HCl} \mathrm{pH} 8.0$ containing $0.1 \%$ Kathon. The dialysed concentrate was subjected to further centrifugation before application to a BioSep Sec 3000 HPLC gel filtration column (Phenomenex, Macclesfield, UK), equilibrated with $15 \mathrm{mM} \mathrm{NaH}_{2} \mathrm{PO}_{4}, 45 \mathrm{mM}$ $\mathrm{Na}_{2} \mathrm{HPO}_{4}$ and $0.15 \mathrm{M} \mathrm{NaCl}$. Fractions were collected according to their absorbance at $280 \mathrm{~nm}$. Those corresponding to the three main peaks detected by the UV-monitor were run on SDS-PAGE gels, silver-stained then transferred to nitrocellulose membranes for Western blotting. The badger bile IgA blots were probed with a panel of commercial anti-IgA and anti-SC polyclonal antibodies with specificity to dog or pig IgA (Bethyl Laboratories Inc., Cambridge, UK); to human IgA (Accurate Chemical and Scientific Co., city, NY, USA); or to cat, goat, and pan-species SC (Accurate Chemical and Scientific Co.) to establish any cross-reactivity to badger IgA.

\subsection{Generation of Monoclonal Antibodies to Badger IgA}

An HPLC purified pool of protein representing the light chain (LC) and SC of badger sIgA was used to immunise six BALB/c mice by the subcutaneous route. The mice were then boosted on four occasions, after 3, 5, 8 and 11 weeks. All mice were bled from the tail vein one week after the second and third boosts and the serum tested for the presence of purified badger sIgA by direct ELISA. One mouse was chosen based on its seroreactivity to sIgA, and given a final boost with the protein. Its 
spleen was removed four days later for the production of B-cell hybridomas. Fifteen stable B-cell clones were produced from the spleen of this mouse. All immunoglobulins produced by the clones were identified as $\mathrm{IgG}$, subclasses $\operatorname{IgG}_{1}$ and $\operatorname{IgG}_{2}$ using an IsoStrip Mouse Monoclonal Antibody Isotyping Kit (Roche Applied Science, Penzberg, Germany).

\subsection{Specificity of Hybridomas for Badger IgA and IgG in a Direct ELISA}

Badger IgG was isolated from the serum of a badger that had tested positive against MPB83 by Brock Test ELISA [7] and purified using a Protein G Sepharose column (Abcam, Cambridge, UK). Purified badger IgG and sIgA, obtained from badger bile as described previously, were coated onto Maxisorp plates (Nunc, Roskilde, Denmark), $100 \mu \mathrm{L} /$ well, diluted in $50 \mathrm{mM}$ carbonate buffer $\mathrm{pH} 9.6$ (1:1500 and 1:45, respectively), overnight at $23^{\circ} \mathrm{C}$. The coating included wells containing buffer alone, to which all other reagents were added to provide a baseline value for each antibody. After three washes with PBS (pH7.2) containing 0.05\% Tween 20 (PBSTw20) plates were blocked with $200 \mu \mathrm{L}$ $3 \%$ casein. After one hour at $37^{\circ} \mathrm{C}$, plates were washed three times with PBSTw20. Fifteen IgA hybridoma supernatants and one peroxidase conjugated anti-IgG monoclonal (CF2, APHA Weybridge, Addlestone, UK) were added in each of the IgG and IgA coated wells at a concentration of $100 \mu \mathrm{L} / \mathrm{mL}$ (1 in 100 dilution). Following incubation for an hour at $37^{\circ} \mathrm{C}$, plates were washed three times with PBSTw20 before addition of a commercial biotinylated anti-mouse IgG antibody (GE Healthcare Life Sciences, Little Chalfont, UK) diluted 1:2000 in PBSTw20, 0.5\% BSA. After one hour at $37^{\circ} \mathrm{C}$ plates were washed three times with PBSTw20 before addition of $100 \mu \mathrm{L} /$ well of Streptavidin Horseradish Peroxidase (diluted 1:4000, GE Healthcare Life Sciences). The wells containing CF2 were incubated with PBSTw20, $0.5 \%$ BSA only. After one hour at $37^{\circ} \mathrm{C}$, plates were washed three times with PBSTw20, before the addition of $100 \mu \mathrm{L} /$ well of tetramethylbenzidine (TMB) substrate (Fisher Scientific UK Ltd., Loughborough, UK). After ten minutes at $24{ }^{\circ} \mathrm{C}$, the reaction was stopped by the addition of $100 \mu \mathrm{L}$ $2 \mathrm{M} \mathrm{H}_{2} \mathrm{SO}_{4}$ per well. The OD value for each hybridoma was divided by the corresponding baseline value without IgA to obtain a ratio. In order to standardise reactions obtained between the hybridomas (with varying concentrations of antibody in the supernatant) each hybridoma was titrated from 1:100 to 1:3500 dilution alongside CF2 at 1/100 as previously. A dilution was selected for each supernatant that gave the same OD as CF2, at its standard working dilution in the Brock Test ELISA [7].

\subsection{Source of Samples}

Samples of blood serum, tracheal aspirate and lymph node (LN) tissue were obtained from experiments published previously involving the endobronchial challenge of captive badgers with $M$. bovis. In the first study, three groups of badgers were infected with different concentrations of $M$. bovis suspension ( $<10$ colony forming units ( $\mathrm{cfu}$ ), approximately $100 \mathrm{cfu}$, or approximately $3000 \mathrm{cfu}$ ), plus a fourth, unchallenged control group [19]. In the second study, three groups of badgers underwent challenge with $M$. bovis (range, 2600-4800 cfu): two groups vaccinated intramuscularly with BCG Danish strain 1331 at two different doses $\left(2-8 \times 10^{5}\right.$ cfu or 10-fold higher) prior to challenge, and one unvaccinated control group [20]. Each study was approved by the local animal ethics committee. The first study (BROC1) was approved by the University College Dublin animal ethics committee prior to the study commencing in 2002, and the second study (VES2) was approved by the APHA animal ethics committee, prior to the study commencing in 2007.

\subsection{Detection of MPB83 Specific-IgA in Serum and Tracheal Aspirate by ELISA}

Recombinant MPB83 (Lionex GmbH, Braunschweig, Germany) was coated onto maxisorb plates at a concentration of $0.5 \mu \mathrm{g} / \mathrm{mL}$. After blocking, serum or tracheal aspirate samples from experimentally infected badgers were diluted in PBSTw20, 0.5\% BSA at a concentration of 1:1 and $100 \mu \mathrm{L}$ added to the wells for one hour. Two wells did not receive the samples, as negative controls. The plates were then washed PBSTw20 and the plates were then incubated with $\mathrm{mAb}(1 / 1)$, diluted 1:500. As previously, commercial biotinylated anti-mouse IgG antibody diluted 1:2000 in PBSTw20, 0.5\% BSA was added. 
After one hour at $37^{\circ} \mathrm{C}$ plates were washed three times with PBSTw20 before addition of $100 \mu \mathrm{L} /$ well of streptavidin horseradish peroxidase. After one hour at $37^{\circ} \mathrm{C}$, plates were washed three times with PBSTw20, before the addition of $100 \mu \mathrm{L} /$ well of tetramethylbenzidine (TMB) substrate (Fisher Scientific UK Ltd., Loughborough, UK). After ten minutes at $24{ }^{\circ} \mathrm{C}$, the reaction was stopped by the addition of

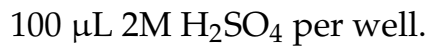

\subsection{Immunohistochemistry Staining}

Badger tissues were removed at necropsy and fixed in zinc salts fixative as previously described [21]. Fixed samples were embedded into paraffin wax and sectioned ( $4 \mu \mathrm{m}$ thickness) onto positive charged microscope slides, de-paraffinised with xylene (VWR International, Lutterworth, UK) and rehydrated through graded ethanols (Hayman, London, UK) before endogenous peroxidase activity was blocked using a hydrogen peroxide/methanol solution (hydrogen peroxide 3\% $v / w$, SLS, Nottingham, UK in methanol, VWR International) for $15 \mathrm{~min}$.

For immunohistochemistry, the slides were assembled into Shandon coverplates (Shandon Scientific, Runcorn, UK) and washed with $0.85 \%$ Tris buffered saline pH7.6 with 0.05\% Tween 20 (TBST) (VWR International). All steps were undertaken at room temperature. The sections were then incubated in normal goat serum (Vector laboratories, Peterborough, UK) diluted (1:66) in TBST for $20 \mathrm{~min}$, before application of IgA monoclonal, pre-conjugated with peroxidase (1/1, APHA). The tissue sections were washed twice ( 5 min each) with buffer after each incubation. Immunolabelling was "visualised" by applying 3,3' diaminobenzidine tetrahydrochloride (DAB), (Sigma-Aldrich Company Ltd., Dorset, UK) and 0.01\% hydrogen peroxide (SLS) for $10 \mathrm{~min}$. Slides were washed with purified water and counterstained with Mayer's haematoxylin (Surgipath, Peterborough, UK) before being dehydrated through graded alcohols, cleared in Xylene and permanently mounted using DPX. Control sections with an irrelevant peroxidase conjugated antibody were used in each IHC run.

\section{Results}

\subsection{Purification and Western Blot, of Badger $\operatorname{sig} A$}

Dialysed concentrate of badger bile was applied to a BioSep Sec 3000 HPLC gel filtration column. Three main peaks were detected by the UV-monitor and the fractions collected and run on SDS-PAGE gels and silver-stained. The three fractions corresponded to the heavy chain (HC), the LC, and SC, based on comparison with the sizes of these molecules in other selected species for which data could found (Table 1). Their identity was confirmed using Western blots probed with a panel of commercial anti-IgA and -SC antibodies, of which only rabbit anti-dog identified HC and LC (Bethyl Laboratories Inc., Cambridge, UK) (Figure 1). Badger sIgA was comprised of heavy and light chain components with SC the most abundant protein associated with sIgA. Size comparison with published data from selected other species showed badger HC, LC and SC to be most similar to baboon (Table 1).

Table 1. Estimated molecular weights of badger sIgA components compared with those of selected other species for which data could be found.

\begin{tabular}{|c|c|c|c|c|c|}
\hline Species. & Source & $\begin{array}{l}\text { H-Chain } \\
\text { (kDa) }\end{array}$ & $\begin{array}{l}\text { L-Chain } \\
\text { (kDa) }\end{array}$ & $\begin{array}{c}\mathrm{SC} \\
(\mathrm{kDa})\end{array}$ & Reference \\
\hline Badger & Bile & 46 & 27 & 66 & This work \\
\hline Rat & $\begin{array}{l}\text { Bile } \\
\text { Milk }\end{array}$ & $\begin{array}{l}50-58 \\
\mathrm{NK}^{1}\end{array}$ & $\begin{array}{c}25-28 \\
\text { NK }\end{array}$ & $\begin{array}{l}66-80 \\
66-71\end{array}$ & [22] \\
\hline $\begin{array}{c}\text { Asian elephant } \\
\text { Guinea pig }\end{array}$ & $\begin{array}{l}\text { Milk } \\
\text { Milk }\end{array}$ & $\begin{array}{c}55-60 \\
52\end{array}$ & $\begin{array}{c}\text { NK } \\
24\end{array}$ & $\begin{array}{l}68-82 \\
72-88\end{array}$ & $\begin{array}{l}{[23,24]} \\
{[25,26]}\end{array}$ \\
\hline Human & $\begin{array}{c}\text { Milk } \\
\text { Colostrum }\end{array}$ & $57-64$ & $25-28$ & $\begin{array}{c}73-90 \\
76\end{array}$ & {$[22,27,28]$} \\
\hline
\end{tabular}


Table 1. Cont.

\begin{tabular}{cccccc}
\hline Species. & Source & $\begin{array}{c}\text { H-Chain } \\
\mathbf{( k D a )}\end{array}$ & $\begin{array}{c}\text { L-Chain } \\
\mathbf{( k D a )}\end{array}$ & $\begin{array}{c}\text { SC } \\
(\mathbf{k D a})\end{array}$ & Reference \\
\hline Pig & Milk & $55-57$ & 23 & $72-90$ & {$[29,30]$} \\
W.I. manatee & Milk & $55-57$ & NK & $70-86$ & {$[24]$} \\
Baboon & Colostrum & $45-66$ & 30 & $66-97$ & {$[31]$} \\
Rabbit & Colostrum & $62-67$ & 23 & 64 & {$[26,32]$} \\
\hline
\end{tabular}

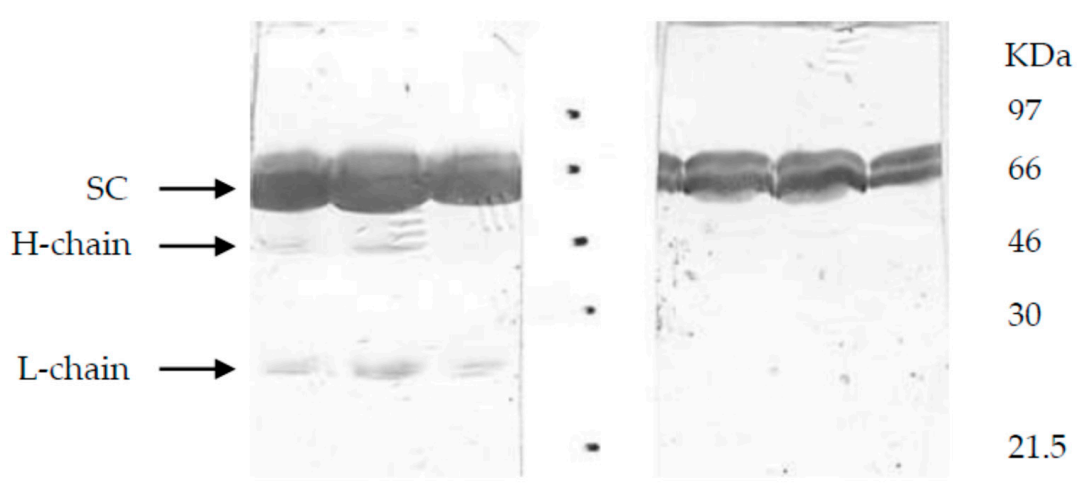

(a)

(b)

Figure 1. Western blot of badger sIgA. Badger sIgA was purified from bile by gel filtration and (a) probed using rabbit polyclonal antibodies to dog IgA (Bethyl Laboratories, UK) and (b) pan-species SC (Bethyl Laboratories, UK). Heavy (H) and light (L) chains of IgA indicated based on published sizes for other species.

\subsection{Recognition by IgA Monoclonal Antibodies of Purified IgA and IgG}

The supernatants from each of the fifteen B-cell clones were first screened for their reactivity to IgA and cross-recognition of badger IgG, by direct ELISA against HPLC purified sIgA from badger bile and IgG purified from serum (Figure 2). Three of the fifteen supernatants $(16 / 2,8 / 1,8 / 2)$, recognised badger IgG. All fifteen supernatants recognised sIgA purified from badger bile (Figure 2). Each monoclonal antibody $(\mathrm{mAb})$ was then used in a direct ELISA against a titration of the purified sIgA. During this phase of the project, a commercial anti-ferret IgA antibody became available and was included in the direct ELISA for comparative purposes. The sensitivity of the ELISA was determined using purified badger bile titrated from 500 down to $15 \mathrm{ng} / \mathrm{mL}$ (Figure 3).

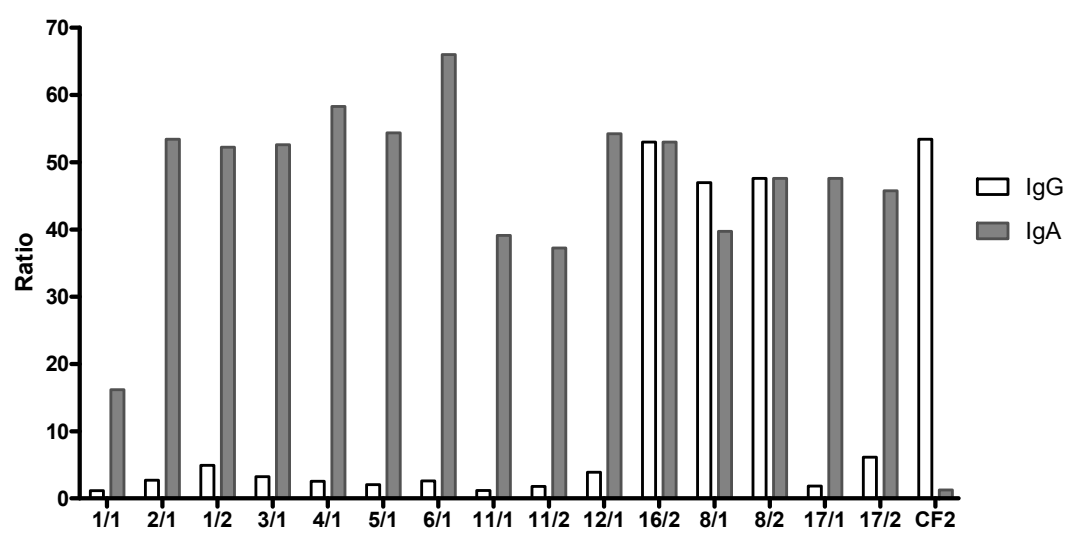

Figure 2. Detection of badger IgA and IgG by mAbs. Ratio value (OD value divided by the corresponding baseline value) for each $\mathrm{mAb}$, showing recognition of sIgA from bile and additionally, of serum IgG by mAbs 16/2, 8/1 and 8/2. CF2 = mAb specific for badger IgG [12]. 


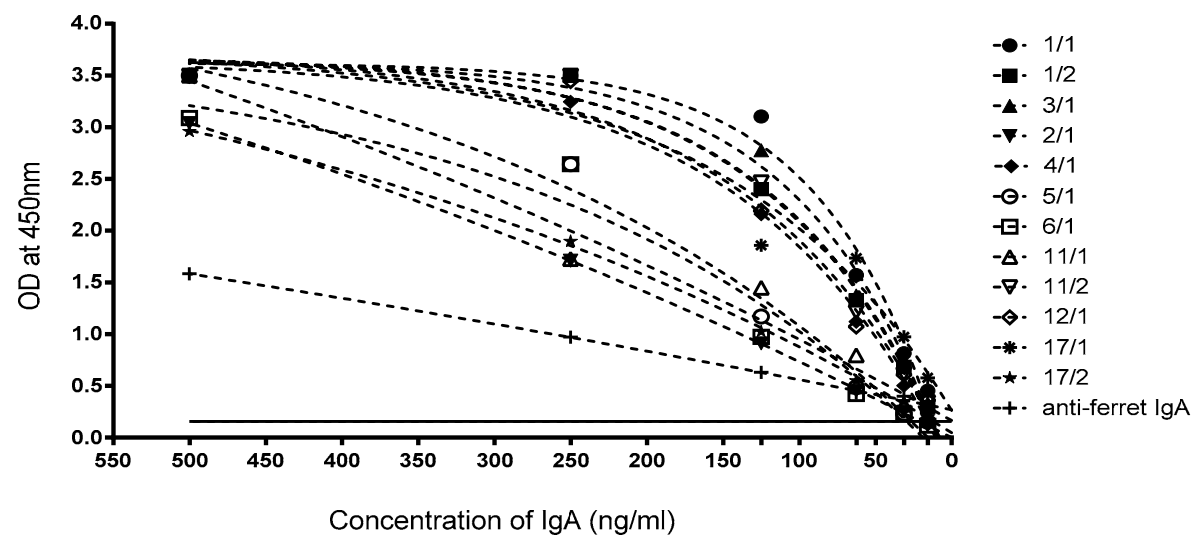

Figure 3. Titration of badger sIgA and recognition by anti-badger IgA monoclonals. Dashed lines show the fits to the data as one phase exponential decay curves (GraphPad Prism version 6.04 for Windows, GraphPad Software, La Jolla, CA, USA, www.graphpad.com). The goodness of fit $\left(\mathrm{R}^{2}\right)$ for these curves varied from $0.9482(17 / 1)$ to $0.9999(2 / 1)$. The solid line represents the background OD, (without the purified $\operatorname{Ig} \mathrm{A})$, plus twice the standard deviation.

\subsection{Recognition of Recombinant MPB83 by IgA in Serum and Tracheal Aspirate}

Serum and tracheal aspirate samples from experimentally infected badgers collected 17 weeks after endobronchial infection with M. bovis at University College Dublin, Ireland [19] were tested against MPB83 in the MPB83-IgA ELISA (Figure 4). Animals given the highest dose of M. bovis (3000 cfu), exhibited the highest IgA responses by ELISA, particularly in serum (Figure 4A). All three badgers that received the highest dose of $M$. bovis were positive, being above the cut-off OD value of 0.097 . Only one tracheal aspirate sample (from animal 180) was above the positive cut-off of 0.437 (Figure 4B).

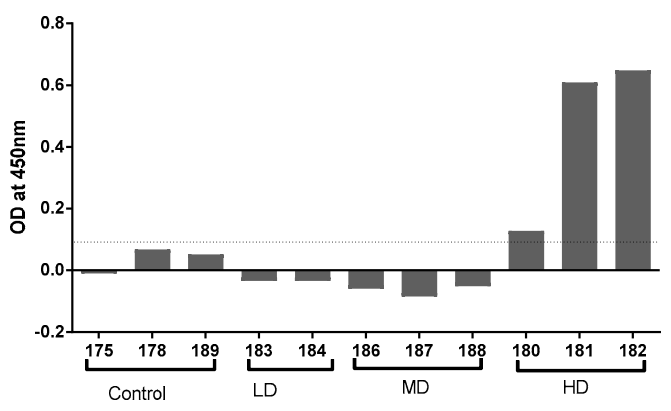

(a)

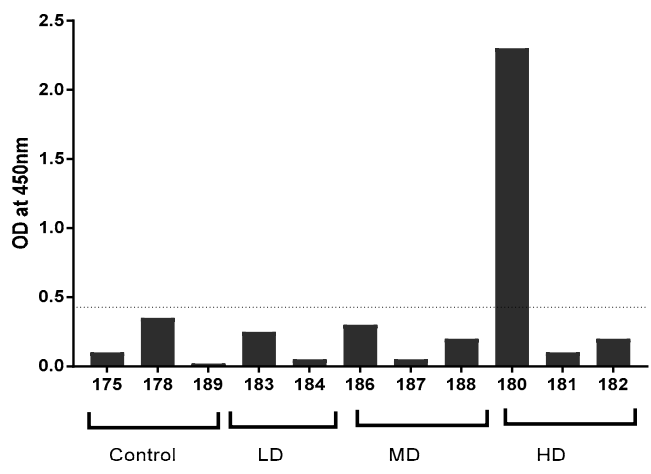

(b)

Figure 4. Recognition of MPB83 antigen by IgA. (a) Serum and (b) tracheal aspirate samples from badgers infected endobronchially with $M$. bovis 17 weeks previously at doses of < 10 cfu (LD), approximately $100 \mathrm{cfu}(\mathrm{MD})$, or approximately $3000 \mathrm{cfu}$, (HD) from [19]. The dashed lines represent the mean ODs for the controls, plus twice the standard deviation. 


\subsection{Immunohistochemical Staining with Peroxidase Labelled IgA Monoclonal}

Right bronchial LN from two badgers infected endobronchially 17 weeks earlier with M. bovis [20] revealed the presence of IgA producing cells. Slide A (Figure 5) from an unvaccinated, infected animal (C037) revealed a typical large granuloma with a necrotic core surrounded by a rim composed of numerous inflammatory cells, including many IgA cells. At post mortem, animal C037 had a greater distribution and severity of M. bovis-induced lesions compared to C067 [20]. In contrast, slide B (Figure 5) is from an infected badger previously vaccinated with BCG (C067), where small solid non-necrotic granulomas are visible with relatively few IgA positive cells.

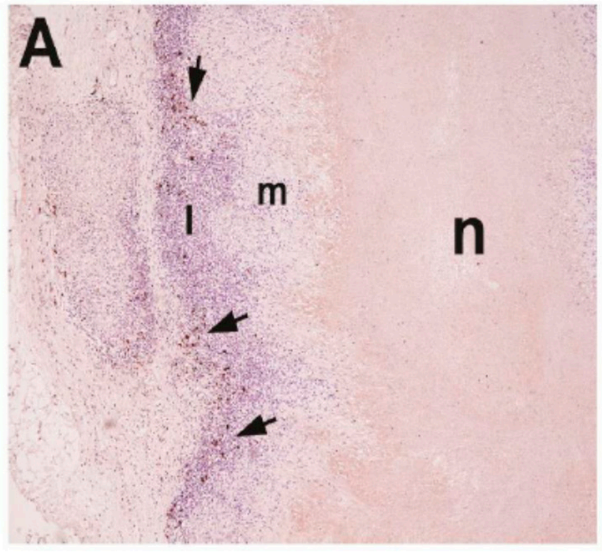

(a)

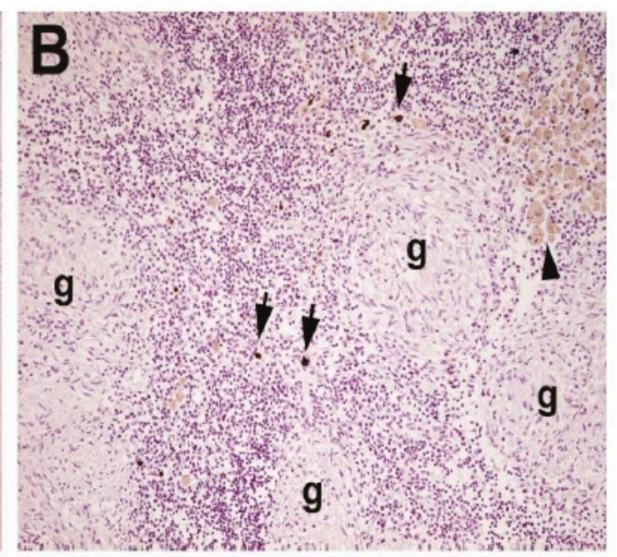

(b)

Figure 5. Immunohistochemical detection of IgA in TB-infected badger lymph node tissue. Tissue sections were prepared from badgers [20]. (a) Unvaccinated control animal (C037) with typical, large necrotic granuloma. IgA-positive cells (arrows) are observed within the outer layers of the granuloma surrounding the necrotic $(\mathrm{n})$ core and the macrophage $(\mathrm{m})$ layer. The majority of IgA positive cells are observed within the rim of lymphocytes (1), at 100× magnification. (b) Animal vaccinated with BCG (C067) with small, solid, non-necrotic granuloma. Few IgA positive cells (arrows) are observed outside small, solid, non-necrotic granulomas (g). Silica-laden macrophages (arrowhead) are also observed, at $200 \times$ magnification.

\section{Discussion}

In humans, $\operatorname{Ig} \mathrm{A}$ is the predominant immunoglobulin in mucosal tissues and secretions, and the second most abundant in serum, and may be important in protection against mycobacterial infection, especially in the respiratory tract. When IgA-deficient mice were infected with BCG, there was more profound pathology in the lung of the deficient mice compared to the wild-type mice [33]. In addition, Reljic et al. demonstrated that the intranasal inoculation of mice with monoclonal IgA against the $\alpha$-crystallin antigen of $M$. tuberculosis can reduce the severity of tuberculous infection in the lungs [34].

To evaluate the antimycobacterial IgA response of badgers and investigate its diagnostic potential, we produced mAbs to badger IgA and characterised them by Western blot and direct ELISA, following sIgA purification from badger bile. On the basis of size, badger sIgA appeared to be comprised of heavy and light chain components, with SC the most abundant protein. Size comparison with published data from other species showed badger HC, LC and SC to be most similar to those of baboon IgA (Table 1).

Three hybridoma supernatants recognised badger IgG, presumably through the recognition of a common epitope in the Fc portion of the immunoglobulin. All mAbs raised specifically to IgA purified from badger bile were found to be more sensitive than the commercial anti-ferret IgA mAb, despite the anticipated high similarity of ferret IgA to badger IgA. The ELISA based on the badger-specific mAbs was determined to have a detection limit of about $20 \mathrm{ng} / \mathrm{mL}$ and a linear detection range was between 15 and $>250 \mathrm{ng} / \mathrm{mL}$. Since $\mathrm{IgA}$ concentrations in canine sera varied from 0.7 to $2.6 \mathrm{mg} / \mathrm{mL}$ [35], but 
were as low as $4 \mu \mathrm{g} / \mathrm{mL}$ in human bronchial secretions [36], this level of sensitivity looked promising for the development of a sensitive assay for badger IgA in secretions such as tracheal aspirate, and serum. The recognition of recombinant MPB83, an immunodominant antigen of M. bovis infected badgers, by IgA in serum and tracheal aspirate is a promising step towards the development of an M. bovis-specific assay. The limit of detection shown in the serum assay (Figure 4A) indicates that animals given the high dose of $M$. bovis and showing the most severe TB lesions [19] have the highest concentration of specific IgA. There appeared to be limited correlation between IgA levels in serum and tracheal aspirate, with only one animal positive in the latter sample type (Figure 4B). This was somewhat surprising given the respiratory nature of the infection, but might be explained by the variable amount of mucus that can be collected by aspiration. Indeed, we have separately evaluated the amount of IgA present in tracheal aspirate samples from different badgers by direct ELISA and found the amounts to be extremely variable (data not shown).

There is emerging evidence that suggests a role for B cells and humoral immunity in the control of intracellular pathogens, such as M. tuberculosis in humans [37]. A study conducted at APHA, reported that in BCG-vaccinated cattle, there was proliferation of B cells along the periphery and within granulomas [38]. The study of IgA and B cells in the granuloma could be a useful tool to study both the pathogenesis of disease caused by M. bovis and to test for a correlation between IgA levels and the severity of pathology or the protection in vaccine efficacy trials.

The most sensitive of the mAbs generated in this study (1/1 and 2/1 specific for $\operatorname{IgA}$, and $8 / 2$ and $16 / 2$ specific for both IgA and IgG), permit the detection of antigen-specific IgA in badgers infected with $M$. bovis. Further work with these reagents is warranted to confirm they are truly specific for IgA, although the data presented here point to this being the case. The serum IgA response to bTB infection is rarely studied, although the combination of IgG and IgA detection provided the best sensitivity of TB detection in people, compared to the use of IgA and IgG alone [39]. The three mAbs with reactivity to both IgG and IgA may permit the simultaneous detection of both immunoglobulins in a test of bTB infection in badgers, whilst inclusion of M. bovis specific antigen, MPB83 indicates scope for development of a specific ELISA.

\section{Conclusions}

Secretory IgA purified from badger bile was used to generate badger-specific anti-IgA mAbs. The most promising $\mathrm{mAbs}$ selected based on titration against badger sIgA were used for the development of an M. bovis-specific assay based on recognition of rMPB83. By ELISA, IgA with specificity to MPB83 was detected in the serum and tracheal aspirate of experimentally-infected badgers. Peroxidase-labelled IgA was also used for the immunohistochemical detection of IgA-positive cells surrounding the necrotic core of granulomas from bTB-infected badgers. With further characterization, these represent new reagents for the study of the IgA response in badgers.

Author Contributions: Conceptualization, D.D., S.L. and M.A.C.; methodology, D.D. and F.J.S.; formal analysis, D.D.; investigation, D.D.; resources, M.A.C. and F.J.S.; data curation, D.D. and M.A.C.; writing-original draft preparation, D.D..; writing-review and editing, M.A.C., S.L. and F.J.S.; visualization, D.D. and F.J.S.; project administration, M.A.C.; funding acquisition, M.A.C.

Funding: This research was funded by Department for Environment, Food and Rural Affairs, grant number SE3213.

Acknowledgments: All animal work was conducted under A(SP)A licences PPL 70/5965 (UK captive badger work) and PPL 70/6183 (mAb production). We thank Eamonn Gormley (University College Dublin) for supplying serum and tracheal aspirate samples from experimentally infected badgers. We thank staff of the Reagent Production Unit (APHA) and members of the Badger Team and Animal Services Unit past and present for their assistance with laboratory and animal procedures.

Conflicts of Interest: The authors declare no conflict of interest. The funders had no role in the design of the study; in the collection, analyses, or interpretation of data; in the writing of the manuscript, or in the decision to publish the results. 


\section{References}

1. Bourne, F.J.; Donnelly, C.A.; Cox, D.R.; Gettinby, G.; McInerney, J.P.; Morrison, W.I.; Woodroffe, R. TB policy and the badger culling trials. Vet. Rec. 2006, 158, 671-672. [CrossRef] [PubMed]

2. Donnelly, C.A.; Woodroffe, R.; Cox, D.R.; Bourne, F.J.; Cheeseman, C.L.; Clifton-Hadley, R.S.; Wei, G.; Gettinby, G.; Gilks, P.; Jenkins, H.; et al. Positive and negative effects of widespread badger culling on tuberculosis in cattle. Nature 2006, 439, 843-846. [CrossRef] [PubMed]

3. Griffin, J.M.; More, S.J.; Clegg, T.A.; Collins, J.D.; O’Boyle, I.; Williams, D.H.; Kelly, G.E.; Costello, E.; Sleeman, D.P.; O'Shea, F.; et al. Tuberculosis in cattle: The results of the four-area project. Ir. Vet. J. 2005, 58, 629-636. [CrossRef] [PubMed]

4. Dalley, D.; Dave, D.; Lesellier, S.; Palmer, S.; Crawshaw, T.; Hewinson, R.; Chambers, M. Development and evaluation of a gamma-interferon assay for tuberculosis in badgers (Meles meles). Tuberc. Edinb. 2008, 88, 235-243. [CrossRef]

5. Chambers, M.A.; Waterhouse, S.; Lyashchenko, K.; Delahay, R.; Sayers, R.; Hewinson, R.G. Performance of TB immunodiagnostic tests in Eurasian badgers (Meles meles) of different ages and the influence of duration of infection on serological sensitivity. BMC Vet. Res. 2009, 5, 42. [CrossRef]

6. Drewe, J.A.; Tomlinson, A.J.; Walker, N.J.; Delahay, R.J. Diagnostic accuracy and optimal use of three tests for tuberculosis in live badgers. PLoS ONE 2010, 5, e11196. [CrossRef]

7. Goodger, J.; Nolan, A.; Russell, W.P.; Dalley, D.J.; Thorns, C.J.; Stuart, F.A.; Croston, P.; Newell, D.G. Serodiagnosis of Mycobacterium bovis infection in badgers: Development of an indirect ELISA using a $25 \mathrm{kDa}$ antigen. Vet. Rec. 1994, 135, 82-85. [CrossRef]

8. Greenwald, R.; Esfandiari, J.; Lesellier, S.; Houghton, R.; Pollock, J.; Aagaard, C.; Andersen, P.; Hewinson, R.; Chambers, M.; Lyashchenko, K. Improved serodetection of Mycobacterium bovis infection in badgers (Meles meles) using multiantigen test formats. Diagn. Microbiol. Infect. Dis. 2003, 46, 197-203. [CrossRef]

9. Chambers, M.A. Review of the diagnosis of tuberculosis in non-bovid wildlife species using immunological methods-An update of published work since 2009. Transbound. Emerg. Dis. 2013, 60 (Suppl. 1), 14-27. [CrossRef]

10. Chambers, M.A. Review of the diagnosis and study of tuberculosis in non-bovine wildlife species using immunological methods. Transbound. Emerg. Dis. 2009, 56, 215-227. [CrossRef]

11. Infantes-Lorenzo, J.A.; Dave, D.; Moreno, I.; Anderson, P.; Lesellier, S.; Gormley, E.; Dominguez, L.; Balseiro, A.; Gortazar, C.; Dominguez, M.; et al. New serological platform for detecting antibodies against Mycobacterium tuberculosis complex in European badgers. Vet. Med. Sci. 2019, 5, 61-69. [CrossRef] [PubMed]

12. Goodger, J.; Russell, W.P.; Nolan, A.; Newell, D.G. Production and characterization of a monoclonal badger anti-immunoglobulin $\mathrm{G}$ and its use in defining the specificity of Mycobacterium bovis infection in badgers by western blot. Vet. Immunol. Immunopathol. 1994, 40, 243-252. [CrossRef]

13. Lesellier, S.; Corner, L.; Costello, E.; Sleeman, P.; Lyashchenko, K.; Greenwald, R.; Esfandiari, J.; Singh, M.; Hewinson, R.; Chambers, M.; et al. Antigen specific immunological responses of badgers (Meles meles) experimentally infected with Mycobacterium bovis. Vet. Immunol. Immunopathol. 2008, 122, 35-45. [CrossRef] [PubMed]

14. Conde, M.B.; Suffys, P.; Lapa, E.S.J.R.; Kritski, A.L.; Dorman, S.E. Immunoglobulin A (IgA) and IgG immune responses against P-90 antigen for diagnosis of pulmonary tuberculosis and screening for Mycobacterium tuberculosis infection. Clin. Diagn. Lab. Immunol. 2004, 11, 94-97. [CrossRef] [PubMed]

15. De Larrea, C.F.; de Waard, J.H.; Giampietro, F.; Araujo, Z. The secretory immunoglobulin A response to Mycobacterium tuberculosis in a childhood population. Rev. Soc. Bras. Med. Trop. 2006, 39, 456-461. [CrossRef] [PubMed]

16. Corner, L.A.; O'Meara, D.; Costello, E.; Lesellier, S.; Gormley, E. The distribution of Mycobacterium bovis infection in naturally infected badgers. Vet. J. 2012, 194, 166-172. [CrossRef] [PubMed]

17. Momotani, E.; Kubo, M.; Ishikawa, Y.; Yoshino, T. Immunohistochemical localization of immunoglobulins in bovine granulomatous lesions. J. Comp. Pathol. 1989, 100, 129-136. [CrossRef]

18. Lemaitre-Coelho, I.; Jackson, G.D.; Vaerman, J.P. Rat bile as a convenient source of secretory IgA and free secretory component. Eur. J. Immunol. 1977, 7, 588-590. [CrossRef]

19. Corner, L.A.L.; Costello, E.; Lesellier, S.; O’Meara, D.; Sleeman, D.P.; Gormley, E. Experimental tuberculosis in the European badger (Meles meles) after endobronchial inoculation of Mycobacterium bovis: I. Pathology and bacteriology. Res. Vet. Sci. 2007, 83, 53-62. [CrossRef] 
20. Lesellier, S.; Palmer, S.; Gowtage-Sequiera, S.; Ashford, R.; Dalley, D.; Dave, D.; Weyer, U.; Salguero, F.J.; Nunez, A.; Crawshaw, T.; et al. Protection of Eurasian badgers (Meles meles) from tuberculosis after intra-muscular vaccination with different doses of BCG. Vaccine 2011, 29, 3782-3790. [CrossRef]

21. Hicks, D.J.; Johnson, L.; Mitchell, S.M.; Gough, J.; Cooley, W.A.; La Ragione, R.M.; Spencer, Y.I.; Wangoo, A. Evaluation of zinc salt based fixatives for preserving antigenic determinants for immunohistochemical demonstration of murine immune system cell markers. Biotech. Histochem. 2006, 81, 23-30. [CrossRef] [PubMed]

22. Altamirano, G.A.; Barranco-Acosta, C.; van Roost, E.; Vaerman, J.P. Isolation and characterization of secretory $\operatorname{IgA}(\operatorname{sigA})$ and free secretory component (FSC) from rat bile. Mol. Immunol. 1980, 17, 1525-1537. [CrossRef]

23. Humphreys, A.F.; Tan, J.; Peng, R.; Benton, S.M.; Qin, X.; Worley, K.C.; Mikulski, R.L.; Chow, D.C.; Palzkill, T.G.; Ling, P.D. Generation and characterization of antibodies against Asian elephant (Elephas maximus) IgG, IgM, and IgA. PLoS ONE 2015, 10, e0116318. [CrossRef] [PubMed]

24. McGee, J.L. Immunological Investigations in the West Indian Manatee (Trichechus manatus) and Asian Elephant (Elephas maximus). Ph.D. Thesis, University of Florida, Gainesville, FL, USA, 2012.

25. McBride, B.W.; Ridgeway, P.; Phillpotts, R.; Newell, D.G. Mucosal antibody response to vaginal infection with herpes simplex virus in pre-vaccinated guinea-pigs. Vaccine 1988, 6, 414-418. [CrossRef]

26. Cunningham-Rundles, C. The Secretory Component and the J Chain. In Immunoglobulins; Litman, G.W., Good, R.A., Eds.; Plenum Publishing Co.: New York, NY, USA, 1978; pp. 155-172.

27. Kobayashi, K. Studies on human secretory IgA comparative studies of the IgA-bound secretory piece and the free secretory piece protein. Immunochemistry 1971, 8, 785-800. [CrossRef]

28. Van Munster, P.J.; Stoelinga, G.B.; Poels-Zanders, S. Evidence of immunochemical differences between free and bound secretory piece. Immunology 1969, 17, 165-174.

29. Bourne, F.J. Structural features of pig IgA. Immunol. Commun. 1974, 3, 154-173. [CrossRef]

30. Phan Thanh, L.; Paraf, A. Purification of three porcine immunoglobulin classes from the same biological source. Ann. Rech. Vet. 1987, 18, 261-267.

31. Shearer, M.H.; Corbitt, S.D.; Stanley, J.R.; White, G.L.; Chodosh, J.; Chanh, T.C.; Kennedy, R.C. Purification and characterization of secretory IgA from baboon colostrum. J. Immunol. Methods 1997, 204, 67-75. [CrossRef]

32. Cebra, J.J.; Small, P.A., Jr. Polypeptide chain structure of rabbit immunoglobulins. 3. Secretory gamma-A-immunoglobulin from colostrum. Biochem. Mosc. 1967, 6, 503-512. [CrossRef]

33. Rodriguez, A.; Tjarnlund, A.; Ivanji, J.; Singh, M.; Garcia, I.; Williams, A.; Marsh, P.D.; Troye-Blomberg, M.; Fernandez, C. Role of IgA in the defense against respiratory infections IgA deficient mice exhibited increased susceptibility to intranasal infection with Mycobacterium bovis BCG. Vaccine 2005, 23, 2565-2572. [PubMed]

34. Reljic, R.; Clark, S.O.; Williams, A.; Falero-Diaz, G.; Singh, M.; Challacombe, S.; Marsh, P.D.; Ivanyi, J. Intranasal IFNgamma extends passive IgA antibody protection of mice against Mycobacterium tuberculosis lung infection. Clin. Exp. Immunol. 2006, 143, 467-473. [CrossRef] [PubMed]

35. Rinkinen, M.; Teppo, A.M.; Harmoinen, J.; Westermarck, E. Relationship between canine mucosal and serum immunoglobulin A (IgA) concentrations: Serum IgA does not assess duodenal secretory IgA. Microbiol. Immunol. 2003, 47, 155-159. [CrossRef] [PubMed]

36. Delacroix, D.L.; Dive, C.; Rambaud, J.C.; Vaerman, J.P. IgA subclasses in various secretions and in serum. Immunology 1982, 47, 383-385.

37. Chan, J.; Mehta, S.; Bharrhan, S.; Chen, Y.; Achkar, J.M.; Casadevall, A.; Flynn, J. The role of B cells and humoral immunity in Mycobacterium tuberculosis infection. Semin. Immunol. 2014, 26, 588-600. [CrossRef]

38. Johnson, L.; Gough, J.; Spencer, Y.; Hewinson, G.; Vordermeier, M.; Wangoo, A. Immunohistochemical markers augment evaluation of vaccine efficacy and disease severity in bacillus Calmette-Guerin (BCG) vaccinated cattle challenged with Mycobacterium bovis. Vet. Immunol. Immunopathol. 2006, 111, 219-229. [CrossRef]

39. Turneer, M.; Van Vooren, J.P.; De Bruyn, J.; Serruys, E.; Dierckx, P.; Yernault, J.C. Humoral immune response in human tuberculosis: Immunoglobulins G, A, and M directed against the purified P32 protein antigen of Mycobacterium bovis bacillus Calmette-Guerin. J. Clin. Microbiol. 1988, 26, 1714-1719.

(C) 2019 by the authors. Licensee MDPI, Basel, Switzerland. This article is an open access article distributed under the terms and conditions of the Creative Commons Attribution (CC BY) license (http://creativecommons.org/licenses/by/4.0/). 